\title{
EDITORIAL
}

\section{Exercise blood pressure in congenital heart disease and in patients after coarctation repair}

\section{Hauser}

Heart 2003;89:125-126

Cardiologists have often described aortic coarctation as "simple" rather than "complex" congenital heart disease; nothing could be further from the truth

$\ldots \ldots \ldots \ldots \ldots \ldots \ldots \ldots$

ystolic blood pressure rises with increased dynamic work load as a result of increasing cardiac output. ${ }^{1}$ At each level of exercise there is a more consistent increase in systolic blood pressure during the first few minutes, and then a steady state is attained. Systolic blood pressure generally correlates with the maximal exercise level achieved. ${ }^{2}$ Normal values of maximal systolic blood pressure can be defined. ${ }^{3}$ After performing maximal exercise, there is a decline in systolic blood pressure, reaching basal levels usually in six to seven minutes, and then often remaining lower than pre-exercise levels for several hours. During exercise there is an immediate vasodilatation of the arteries and capillaries in active skeletal muscle tissue because of increased metabolic demands in contrast to tissue that is not involved where peripheral vascular resistance increases. The total result is a decrease in overall systemic vascular resistance. ${ }^{4}$ While systolic blood pressure increases simultaneously, diastolic blood pressure usually remains about the same.

During leg exercise using a treadmill or bicycle, blood pressure at the arm can easily be measured, whereas leg recordings, for assessing eventual blood pressure gradients in patients after coarctation repair, are hampered because of movement artefacts. Therefore arm-leg gradients during ergometry can only be measured by invasive methods. Several investigators have attempted to overcome this problem by simultaneous measurement of arm and leg blood pressures immediately after ergometry. The time interval from end of exercise to blood pressure measurement varied between one and two minutes, and, therefore, these results were influenced by the well documented, substantial decrease in heart rate and arterial pressure during the first two minutes of resting. Because blood pressure already decreases in a very short time interval of about 30 seconds, only peak exercise pressure values of the arms were considered for evaluation of exercise induced hypertension.

Correspondence to: Dr Michael Hauser, Deutsches Herzzentrum /TU München, Department of Paediatric Cardiology, Lazarettstraße 36, 80636 Munich, Germany; hauser@dhm.mhn.de

\section{PATHOLOGIC BLOOD PRESSURE RESPONSE}

An inadequate increase or fall in systolic blood pressure during exercise can be caused by aortic outflow obstruction, severe mitral disease, left ventricular dysfunction or limited compliance of the systemic ventricle. Additionally, conditions of reduced preload can affect significantly the systolic blood pressure by a reduction of the stroke volume during exercise. ${ }^{5}$ Since changes of blood pressure also depend on peripheral resistance, they reflect more than the contractile function of the left ventricle.

A number of studies have identified persistent cardiovascular abnormalities in asymptomatic children and adolescents after coarctation repair even after successful surgical management in childhood. Abnormally high systolic blood pressures commonly occur after coarctation repair with exercise, even in patients who are normotensive at rest. Occult coarctation, persistent alterations in baroreceptor function, ${ }^{6}$ persistent hyperresponsiveness of the renin-angiotensin system, ${ }^{7}$ abnormal response to sympathomimetic agents, ${ }^{8}$ and persistent elevation of upper body vascular resistance with structural alterations in the central and peripheral arteries ${ }^{9}$ have all been proposed as possible explanations for these responses. The adaptations of the paediatric left ventricle to pressure overload from coarctation of the aorta with enhanced systolic function, increased left ventricular mass, and subnormal left ventricular wall stress have been shown to persist in normotensive patients without significant blood pressure gradients after coarctation repair. ${ }^{10}$ Increased aortic stiffness combined with a mild degree of residual aortic narrowing would lead to persistent elevation of left ventricular afterload after coarctation repair, and may account for the persistence of left ventricular hyperkinesis and mass. Cardiac index at rest and exercise has been shown to be similar in normal children and in those after coarctectomy. In children with similar cardiac indices at exercise, increased stiffness in the arterial bed in coarctectomy patients would lead to a relative increase in exercise blood pressure when they were compared with normal subjects having a normal arterial bed.

Elevation of left ventricular mass or blood pressure at rest or/and at exercise after coarctation repair is of concern because both variables are independent risk factors for cardiovascular morbidity and mortality in adults. ${ }^{11}$ The magnitude of left ventricular mass and blood pressure elevation after coarctation repair likely has many causes.

The pathophysiologic background of exercise induced hypertension in patients after coarctation repair underlines the results of Swan and colleagues in this issue of Heart, who could not find a significant correlation between residual narrowing (that is, Doppler gradient at the coarctation site) and systolic exercise blood pressure. ${ }^{12}$ 
However, Doppler gradients are not reliable for detecting residual narrowing of the aorta after coarctation repair. ${ }^{13}$ Poor correlation and limits of agreement between Doppler maximal instantaneous gradients and catheterisation maximal instantaneous and peak-to-peak gradients have been reported.

Although there is a poor correlation between systolic hypertension on exercise and the presence of anatomic recoarctation, stress testing is still a valuable tool for making a decision about antihypertensive treatment and drug monitoring in the absence of significant narrowing at the coarctation site.

\section{ARM-LEG PRESSURE GRADIENTS}

The many exercise studies in postoperative coarctation patients have yielded surprising and often conflicting results. It is surprising that after successful coarctation repair, abnormally high systolic blood pressures and significant arm-leg blood pressure gradients are induced with exercise testing. ${ }^{14}$ Factors which may be responsible for or involved in the abnormal findings include: arterial hyperactivity (that is, increased systemic arterial resistance); aortic arch gradients as a result of discrepancies of aortic arch growth of the transverse arch; increased aortic stiffness proximal to the coarctation repair; and, as mentioned above, increased left ventricular mass and contractility - a hyperdynamic state which produces increased acceleration of left ventricular ejection and thus increased systolic blood pressure. ${ }^{10}$ Blood pressure differences between arms and legs at rest reflect severity of narrowing in aortic coarctation and correlate with invasive haemodynamic findings. ${ }^{15}$ Therefore, persistent gradients are used to evaluate success of surgery. However, the correlation between exercise arm-leg gradient and narrowing of the area of resection and reanastomosis, measured by imaging techniques, is questionable. ${ }^{16}$ A positive arm-leg gradient of $40-50 \mathrm{~mm} \mathrm{Hg}$ often reflects physiologic circulatory adaption to exercise. During leg exercise (treadmill, bicycle) increased cardiac output leads to an increase in arm blood pressure, whereas vasodilatation in the working musculature leads to a small decrease in leg blood pressure ${ }^{17}$ Pathological elevated exercise gradients in coarctation patients could either be caused by some residual narrowing or more probably reflect a hypertensive response of the arms, which is a well known complication in long term follow up after coarctation resection. This strongly supports the theory that arterial dysfunction of the precoarctation vascular bed is not influenced by surgery and plays a crucial role in persistent hypertension in long term follow up after coarctectomy. Paradoxically, cardiologists have often described aortic coarctation as "simple" rather than "complex" congenital heart disease; nothing could be further from the truth. The complexity of aortic coarctation becomes evident when caring for the adolescent or adult who has had previous surgical repair.

\section{REFERENCES}

1 Guyton A. The relation of cardiac output and arterial pressure control. Circulation 1981;64:1079

2 Bevegard B, Shepard J. Regulation of the circulation during exercise in man. Physiol Rev 1967;47:178.

3 Nordenfelt I, Adolfsson L, Nolsson JE, et al. Reference values for exercise tests with continuous increase in work load. Clin Physiol 1985;5:161-72.

4 Froelicher V, Myers J, Follansbee W, et al. Interpretation of hemodynamic responses to exercise testing: exercise capacity, heart rate, and blood pressure. In Froelich V, Myers J, Follansbee W, et al, eds. Exercise and the heart, 3rd ed. St Louis: Mosby, 1993:71.

5 Gewillig $M H$, Lundström UR, Bull C et al. Exercise responses in patients with congenital heart disease after Fontan repair: patterns and determinants of performance. J Am Coll Cardiol 1990;15:1424-32.

6 Guenthard J, Zumsted U, Whyler F. Arm-leg pressure gradients on late follow up after coarctation repair. Eur Heart J 1996;17:1572-5.

7 Ross RD, Clapp SK, Gunther S. Augmented norepinephrine and renin output in response to maximal exercise in hypertensive coarctectomy patients. Am Heart J 1992;123:1293-9.

8 Hauser M, Kuehn A, Wilson N. Abnormal responses for blood pressure in children and adults with surgically corrected aortic coarctation. Cardiol Young 2000;10:353-7.

9 Sehested J, Baandrup U, Mikkelsen E. Different reactivity and structure of the prestenotic and poststenotic aorta in human coarctation: implications for baroreceptor function. Circulation 1982;65:1050-65

10 Ong CM, Canter CE, Gutierrez FR, et al. Increased stiffness and persistent narrowing of the aorta after successful repair of coarctation of the aorta: relationship to left ventricular mass and blood pressure at rest and with exercise. Am Heart J 1992;123:1594-600.

11 Levy D, Garrison RJ, Savage DD, et al. Prognostic implications of echocardiographically determined left ventricular mass in the Framingham heart study. N Engl J Med 1990;322:1561-6.

12 Swan L, Goyal S, Hsia C, et al. Exercise systolic blood pressures are of questionable value in the assessment of the adult with a previous coarctation repair. Heart 2003;89: 189-92.

13 Chan KC, Dickinson DF, Wharton GA, et al. Continuous wave Doppler echocardiography after surgical repair of coarctation of the aorta. $\mathrm{Br}$ Heart J 1992:68:192-4.

14 Ruttenberg HD. Pre- and postoperative exercise testing of the child with coarctation of the aorta. Pediatr Cardiol 1999;20:33-7.

15 Guenthard J, Wyler F. Exercise-induced hypertension in the arms due to impaired arterial reactivity after successful coarctation repair. Am J Cardiol 1995;75:814-17

16 Kappetein PA, Guit GL, Bogers JC, et al. Noninvasive long-term follow up after coarctation repair. Ann Thorac Surg 1993;55:1 153-9.

17 Engvall J, Nylander E, Wranne B. Arm and ankle blood pressure response to treadmill exercise in normal people. Clin Physiol 1989;9:517-24. 